\title{
DUAS TESES SOBRE A EVIDÊNCIA: O “DUPLO DESLOCAMENTO" PROPEDÊUTICO À FENOMENOLOGIA DE HUSSERL
}

\author{
TWO THESES ON THE EVIDENCE: THE "DOUBLE DISPLACEMENT" \\ PROPAEDEUTIC TO HUSSERL'S PHENOMENOLOGY
}

\author{
CARLOS Diógenes CôRTES TOURINHO ${ }^{1}$ \\ Universidade Federal Fluminense (UFF) - Brasil \\ cdctourinho@gmail.com
}

\begin{abstract}
RESUMO: O presente artigo aborda duas teses principais sobre a evidência em Husserl. A primeira delas afirma que a evidência é o "primeiro princípio metódico" a reger a investigação de um objeto, ao passo que a segunda afirma que "toda evidência predicativa implica em uma evidência prépredicativa". No exame da primeira, encontramos o que assegura a passagem da "presunção" para a "presença" de algo visado; já a segunda supõe uma reflexão sobre o alcance e limite da evidência, revelando-nos o deslocamento da percepção sensível para a percepção categorial. Se a primeira tese consiste em uma lição preliminar sobre o método fenomenológico, a segunda contém a descoberta da intuição categorial e sua relação com a experiência pré-predicativa.
\end{abstract}

PALAVRAS-CHAVE: Edmund Husserl. Intencionalidade. Evidência. Intuição sensível. Intuição categorial. Experiência pré-predicativa.

\begin{abstract}
The present paper approaches two main theses on the evidence in Husserl. The first of these states that evidence is the "first methodical principle" to govern the investigation of an object, while the second states that "all predicative evidence implies pre-predicative evidence". In examining the first, we find what ensures the transition from "presumption" to "presence" of something intented; the second supposes a reflection on the range and limit of the evidence, revealing to us the shift from the sensitive perception to the categorical perception. If the first thesis consists of a preliminary lesson on the phenomenological method, the second contains the discovery of categorical intuition and its relation to pre-predicative experience.
\end{abstract}

KEYWORDS: Edmund Husserl. Intentionality. Evidence. Sensitive intuition. Categorical intuition. Pre-predicative experience.

\section{INIRODUÇÃO}

Um olhar atento sobre a Primeira Meditação de Meditações Cartesianas (1931) - obra que, como sabemos, resultou da famosa conferência proferida por

\footnotetext{
1 Doutor em Filosofia pela PUC-Rio. Professor Associado II do Departamento de Filosofia e Professor Efetivo do Programa de Pós-Graduação em Filosofia da Universidade Federal Fluminense - UFF/ Niterói-RJ, Brasil. Membro do Núcleo de Sustentação do GT de Fenomenologia da ANPOF.
} 
Husserl na Sorbonne em Paris, dois anos antes - revela-nos duas teses principais as quais podemos atribuir, de certo modo, um sentido "propedêutico" no programa da fenomenologia husserliana. A primeira delas afirma-nos que a evidência consiste no "primeiro princípio metódico" (erstes methodisches Prinzip), destinado a reger, na investigação de um objeto, todos os passos ulteriores, ao passo que a segunda assinala que "toda evidência predicativa implica em uma evidência prépredicativa" (Prädikative Evidenz schließt vorprädikative ein) (HUSSERL, [1931] 1973, \ 4, p. 52). Respectivamente, como se vê, tais teses remetem-nos para a "evidência" (Evidenz) da presença de algo visado: seja para considerá-la um "primeiro princípio" quando falamos de método em fenomenologia, seja para discernir os seus "tipos" ("predicativo" e "pré-predicativo"), quando refletimos sobre o alcance e limite do que se evidencia. Pode-se dizer que ambas as teses já se encontram formuladas desde a primeira edição do segundo volume de Investigações Lógicas (1901) - obra que, segundo Husserl, constitui uma espécie de "marco" no caminho da fenomenologia - mantendo-se, dada a sua importância, indissociavelmente conservadas ao longo do itinerário husserliano. Neste sentido, não causa surpresa que as teses em questão sejam, muito claramente, preservadas por mais de três décadas após a publicação da referida edição. No que concerne à primeira delas, poderíamos considerá-la como uma "primeira palavra" sobre o método fenomenológico e, portanto, sobre o caminho por intermédio do qual podemos, em termos husserlianos, "preencher intuitivamente" um visar meramente significativo, evidenciando, por conseguinte, a presença da coisa visada (ou do seu estado-de-coisa). Para Husserl, tal "preenchimento" (Erfüllung) equipara-se, propriamente, ao conhecimento (daí a sua relevância em termos metodológicos) ${ }^{2}$. Afinal, como o autor insiste em dizer, em diferentes momentos do seu itinerário, a ciência não quer apenas formular juízos sobre os seus objetos, mas, antes sim, quer fundá-los na evidência ${ }^{3}$. A primeira tese identifica, portanto, no princípio de "somente julgar na evidência" (nur in Evidenz zu urteilen), aquilo que o método fenomenológico supõe de mais elementar: só a evidência da presença de algo visado intencionalmente assegura-nos o conhecimento. Do contrário, por mais forte que seja a nossa convicção acerca de um juízo qualquer, o mesmo se manterá como uma mera "presunção" (Vermeinen) caso não esteja fundado na evidência.

A passagem à segunda tese chega-nos pela reflexão sobre os limites na evidenciação dos objetos, revelando-nos tipos de evidência. Ao tratar do alcance da evidência e dos seus tipos ("predicativo" e "pré-predicativo"), a segunda tese coloca-nos frente à descoberta husserliana - anunciada no famoso Capítulo 6 da Sexta Investigação de Investigações Lógicas - segundo a qual podemos identificar, quando expressamos um objeto da percepção sensível, um "excedente"

\footnotetext{
${ }^{2}$ Neste sentido, Husserl é bem claro ao dizer, no $₫ 16$ do capítulo 3 da Sexta Investigação de Investigaçôes Lógicas: "Equiparamos o preenchimento ao conhecimento (em sentido estrito)" ("Wir hatten Erfüllung mit Erkennung (im engeren Sinn)...") (HUSSERL, E. [1901] 1913b / 1968, §16, p. $65)$.

${ }^{3}$ Sobre o princípio de "somente julgar na evidência" (nur in Evidenz zu urteilen), Husserl nos diz, na Lição 2 do Volume I de Filosofia Primeira, que: "Um ato de julgamento verdadeiro é um ato de julgamento que se confirma necessariamente ou pode se confirmar na evidência" (HUSSERL, [1923/1924] 1956, p. 30). O mesmo princípio seria ainda retomado no $₫ 4$ de Meditações Cartesianas (Cf. HUSSERL, E. [1931/1929] 1973, \ 4).
} 
(Überschub) na significação que não encontra, no ato simples da percepção, um correspondente objetivo capaz de preenchê-lo intuitivamente. Por conta desta descoberta, Husserl é forçado a ampliar, conforme sabemos, os conceitos indissociáveis de "percepção" (Wahrnehmung) e de "objeto" (Gegenstand), estendendo-os, a partir de então, para além da sensibilidade e, portanto, em direção à esfera judicativa. Nela, o juízo expressa uma nova significação à coisa percebida inicialmente, permitindo-nos pensar o seu "estado-de-coisa" (Sachverhalt).Tratam-se, portanto, com as duas teses mencionadas sobre a evidência, de um "duplo deslocamento", de suma importância à fenomenologia husserliana: na primeira, a evidência da presença de algo torna possível a "passagem" da intenção meramente significativa para o seu preenchimento intuitivo, assegurando-nos, metodologicamente, o conhecimento do que é visado nesta intenção; ao passo que, na segunda, a mera atribuição do ser (em sentido predicativo) à coisa percebida sensivelmente obriga-nos, pelos próprios limites da captação sensível, a um "novo deslocamento", conduzindo-nos à passagem para a esfera judicativa na qual se pode, mediante formas categoriais objetivas, relacionar os termos da relação proposicional, permitindo-nos, assim, pensar um "estado" da coisa visada que não poderia se mostrar, enquanto tal, na percepção sensível. Dividido em duas partes, o presente artigo consiste, portanto, em abordar, a partir de passagens específicas da Primeira e da Sexta Investigação de Investigações Lógicas (1901) - recorrendo, eventualmente, a parágrafos da Primeira Meditação de Meditações Cartesianas (1931), bem como da Segunda Seção de Lógica Formal e Lógica Transcendental (1929) - as teses em questão sobre a evidência, destacando o "duplo deslocamento" operado pelas mesmas, explicitando, por fim, o caráter propedêutico que assumem no programa da fenomenologia de Husserl.

\section{SOBRE A PRIMEIRA IESE: A EVIDÊNCIA COMO "PRIMEIRO PRINCíPIO METÓDICO"}

A análise da tese da evidência como um "princípio metódico" supõe uma distinção - anunciada pela primeira vez em 1901, na Primeira Investigação de Investigações Lógicas - para a qual Husserl retorna, insistentemente, ao longo de quase quatro décadas, chegando mesmo a considerá-la, em 1929, um "progresso decisivo da fenomenologia frente ao passado filosófico” (HUSSERL, [1929] 1981, p. 145): trata-se da distinção entre atos intencionais meramente significativos e seus eventuais "preenchimentos intuitivos", decorrentes da evidência da presença da coisa visada. Tal distinção supõe, por sua vez, a doutrina da qual Husserl jamais abdicou - assimilada desde 1884, nos cursos de Brentano - segundo a qual toda consciência é "consciência de algo" (Bewubtseins von etwas). A doutrina da intentio se desdobra, portanto, já no começo da Primeira Investigação de Investigações Lógicas, em uma dualidade fundamental que, ao se abrir, revela a distinção entre os referidos atos intencionais e seus preenchimentos intuitivos, assegurando-nos, assim, não apenas a "função simbólica" (symbolischen Funktion) de tais atos, mas também, graças a eventuais sínteses dos mesmos com seus respectivos preenchimentos, a sua "função de conhecimento" (Erkenntnisfunktion), conforme nos esclarece Husserl desde o $\ 9$ da Primeira Investigação (HUSSERL, [1901] 1913 a, 1968). 
O visar intencional é, antes de tudo, para Husserl, independentemente de uma eventual evidência da presença do que é intencionado, um visar "meramente significativo" que, na ausência de tal evidenciação, permanece como mera intenção "vazia", ou mesmo, como um mero "presumir" acerca daquilo que é visado no próprio ato. Porém, para além do aspecto "semântico" dos atos intencionais (para o qual Husserl se volta, inicialmente, nos parágrafos iniciais da Primeira Investigação, ao examinar os sentidos do signo como "índice" e como "expressão" no discurso comunicativo dialógico $)^{4}$, quando consideramos a dimensão "cognitiva" da intencionalidade, inevitavelmente, somos deslocados para aquilo que assegura a síntese (ou a "unidade intimamente fundida") entre atos intencionais significativos e intuitivos: a evidência da presença da coisa visada. Em sentido mais amplo, a evidência nos proporciona, conforme esclarece Husserl no $\S 5$ de Meditações Cartesianas: "uma experiência de ser e da sua maneira de ser" (Evidenz ist in einem allerweitesten Sinne eine Erfahrung von Seiendem und SoSeiendem) (HUSSERL, [1931/1929] 1973, p. 52). Nela, a coisa intencionada não é apenas visada de forma distante ou "remota" (sachfernen), como objeto de uma intenção meramente significativa. Antes disso, a coisa visada nos é, de certo modo, presente "ela própria", em seu estado de coisa "ele próprio". Trata-se, portanto, de um "acréscimo" sem o qual não poderíamos, nos termos de Husserl, aspirar nada de definitivo, ou mesmo qualquer "validade final" (Endgültigkeit) (HUSSERL, [1931/1929] 1973, \$5).

Tem-se, portanto, nos atos intencionais, algo como uma transposição (Überführung) da "presunção" para a "presença" da coisa visada. Como nos diz Husserl, no $₫ 4$ de Meditações Cartesianas, tal transposição assume o "caráter do preenchimento do mero visar" (Charakter der Erfüllung der bloßen Meinung) (HUSSERL, [1931/1929] 1973, \$4, p. 51). Eis o primeiro deslocamento do qual falávamos na introdução do presente artigo. A passagem em questão é assegurada na medida em que a intenção significativa - inicialmente, vazia de preenchimentos intuitivos e, portanto, ainda na condição de um mero "presumir" - torna-se, por meio da evidenciação, confirmada (ou "ilustrada") pela presença intuitiva da coisa (ou do estado da coisa) visada. Daí Husserl considerar, no \ 5 das mesmas Meditações, a evidência como um "primeiro princípio metodológico" (erstes methodisches Prinzip), destinado a reger, na investigação de um objeto, todos os passos ulteriores (HUSSERL, [1931/1929] 1973). Trata-se de algo elementar e, por isso mesmo, assume como "primeiro princípio", um sentido propedêutico quando tratamos do método fenomenológico. Afinal, sem que pudesse estar fundada na evidência, ou na "efetiva doação das coisas" (die wirkliche Selbstgebung der Sachenreicht), a referida transposição do "presumir" para a "presença" da coisa visada não seria possível. Como lembra o autor, ao asserir predicações sobre os objetos, a ciência não quer apenas formular, de maneira geral, juízos acerca dos mesmos, mas fundá-los ou verificá-los (à tout moment) na evidência, não podendo

\footnotetext{
${ }^{4}$ Sobre as primeiras palavras de Husserl acerca dos sentidos de signo como "índice" e como "expressão" no discurso dialógico no Capítulo 1 da Primeira Investigação, conferir, especificamente, os IS 1-8 (HUSSERL, [1901] 1913 a, 1968, IS 1-8). Sobre o tema em questão, conferir ainda as considerações de Jacques Derrida (DERRIDA, J. La voix et le phénomène. Paris: Presses Universitaires de France, 1972, pp. 17-27).
} 
atribuir validade a um juízo qualquer se não tiver extraído tal validade judicativa do que é evidente. Do contrário, os juízos permaneceriam como meras intenções significativas. O ato de julgar é, antes de tudo, uma intenção e, em geral, uma simples "presunção" (Vermeinen) de que uma coisa seja isso ou aquilo. Neste caso, o que é afirmado pelo juízo é apenas coisa ou estado de coisa presumido, visado pelo pensamento e, portanto, "estado de coisa pensado" (Denksachverhalt). Em geral, para Husserl, enunciar proposições judicativas, por mais viva que seja a convicção em tal enunciação, não é ainda "conhecer", no sentido autêntico da palavra. Tal intenção puramente presuntiva deve, inicialmente, demonstrar o seu valor de verdade, algo que somente se torna possível pela adequação da intenção inicial a uma intuição correspondente, ao localizar diante do olhar, a coisa "ela mesma" (o seu estado "ele próprio"), revelando-a, nos termos de Husserl, "in persona" . Trata-se, em resumo, de tornar um mero visar um estado de coisa em uma intenção "fundada" ("begründet"), no sentido de "elevá-la à evidência" ("einsichtig gemacht"). Com isso, eventualmente, deparamo-nos com outro julgar intencional, no qual temos, de certo modo, a presença à consciência do que é julgado, ou como gosta de dizer Husserl: a "efetiva doação das coisas" (die wirkliche Selbstgebung der Sachenreicht) (HUSSERL, [1931] 1973, p. 54). Dá-se uma conformação entre o ato de visar e seu preenchimento intuitivo, fazendo com que o julgamento meramente presuntivo torne-se objetivamente verdadeiro, na medida em que o mesmo se confirma na evidência. Tem-se, então, a distinção essencial e propedêutica - anunciada desde os primeiros parágrafos da Primeira Investigação de Investigações Lógicas - entre atos intencionais "significativos" e "intuitivos", além de uma síntese entre os mesmos, convertendo-os, a partir de um recobrimento do primeiro ato pelo segundo, em uma "unidade de recobrimento". Os atos intencionais significativos encontrar-se-iam, portanto, uma vez preenchidos intuitivamente, fundados na evidenciação das coisas.

Fica, então, claro que a tese sobre o "princípio metódico da evidência" se mantém, conforme vimos, alinhada a um primeiro deslocamento: a passagem do ato intencional como um mero "presumir" à intuição evidente da presença daquilo que é visado no próprio ato, assegurando, assim, o seu preenchimento intuitivo. Se a passagem em questão nos permite notar um "primeiro deslocamento" operado pela referida tese, paralelamente, a segunda tese - segundo a qual "toda evidência predicativa implica em uma evidência pré-predicativa" - irá apontar para um "novo deslocamento". Entre as duas teses, deparamo-nos, segundo Husserl, com uma tarefa: a de refletir sobre o alcance e limite da evidência de algo visado, isto é, de avaliar até onde se estende, para mim, a efetiva doação das coisas elas próprias (HUSSERL, [1931/1929] 1973, 』 5). No exercício desta tarefa, dá-se uma nova descoberta, por meio da qual se revela a relação entre tipos específicos de evidência. Vejamos, então, mais detidamente, o que supõe a segunda tese e qual a sua relação com a primeira.

\footnotetext{
5 Sobre a teoria da adequação em Husserl (Cf. TOURINHO. Sobre a adequação entre intenção significativa e preenchimento intuitivo nas Investigações Lógicas de Husserl. In: Cognitio: Revista de Filosofia, v.16, n. 2, 2015, pp. 361-374).
} 


\section{SOBRE A SEGUNDA TESE: "TODA EVIDÊNCIA PREDICATIVA IMPLICA EM UMA EVIDÊNCIA PRÉ-PREDICATIVA"}

O ponto de partida para a apresentação da segunda tese sobre a evidência remete-nos para a Sexta Investigação, na qual Husserl retoma a temática do conhecimento e, por conseguinte, da distinção e síntese entre atos intencionais significativos e seus respectivos preenchimentos intuitivos, abordados, conforme vimos, desde o Capítulo 1 da Primeira Investigação. Mais precisamente, o ponto de partida em questão remete-nos para o conhecido Capítulo 6 da Sexta Investigação, momento no qual Husserl apresenta-nos - a partir do problema do preenchimento das formas categoriais objetivas - a descoberta da "intuição categorial". A tarefa de refletir sobre o alcance e limite daquilo que se evidencia conduz o autor à constatação de um "novo deslocamento": a mera atribuição do ser (em sentido predicativo) à coisa percebida sensivelmente obriga-nos, pelos próprios limites da captação sensível, a passar para a esfera judicativa na qual se pode, mediante formas categoriais objetivas, relacionar os termos da relação proposicional, permitindo, assim, pensar um "estado" da coisa visada que não poderia se mostrar, enquanto tal, na percepção sensível. Como esclarece Husserl, no $₫ 40$ do Capítulo 6 da Sexta Investigação: percebo um papel e expresso a minha percepção dizendo "papel branco" (onde branco corresponde ao momento de cor do objeto que aparece, reconhecido em sua totalidade como "papel"); permanece, contudo, implícito nesta percepção, um "excesso na significação" (Überschuß in der Bedeutung) que não encontra, na captação sensível do objeto, um correspondente objetivo capaz de confirmá-lo intuitivamente: quando digo "papel branco", quero dizer, "papel existente branco" (weiß seiendes Papier) (HUSSERL, [1901] 1913b, 1968, p. 131). Há aí algo como uma "forma complementar" (ergänzenden Form) que não pode, por sua vez, ser alcançada pelo trabalho da percepção sensível, pois, na esfera desta percepção - conforme esclarece Husserl ao final do $₫ 43$ do mesmo capítulo - não encontramos nenhum correlato objetivo possível (e, portanto, nenhum preenchimento possível) para uma significação tal como a da palavra "ser" (Sein) (HUSSERL, [1901] 1913b, 1968, 』 43). A constatação deste limite força-nos a um deslocamento para a esfera judicativa. Daí Husserl afirmar que: "...é seguramente correto que um ser apenas é concebível no julgar" (...es sicherlich richtig, dab ein Sein nur im Urteilen erfabbar ist) (HUSSERL, [1901] 1913b, 1968, \ 44, p. 140), de modo que se o ser vale em sentido predicativo, então, devemos supor um "estado" da coisa visada, cuja evidência se dá através de "percepções de estados de coisas" (Sachverhaltwahrnehmungen).

Segundo Husserl, a percepção sensível é, como tal, um ato "simples", quer dizer, o objeto sensível - a despeito de suas determinações singulares, cujas variações não impedem que ele seja o mesmo objeto - é captado diretamente pela própria percepção, doando-se a ela imediatamente. Neste sentido, o autor nos diz, no $₫ 46$ do Capítulo 6 da Sexta Investigação, que, "em modo simples" (in schlichter Weise), a percepção sensível torna-se um "ato fundamental de novos atos" (Grundakt von neuen Akten), uma vez que prescinde de outros atos que constituam outros objetos (HUSSERL, [1901] 1913b, 1968, §46). Captado pelo ato simples da percepção sensível, dizemos que o objeto como um todo é 
"explicitamente" dado ( "explizite" gegeben). Todavia, cada uma de suas partes (parte em sentido amplo) encontra-se nele presente, porém, "implicitamente" dada ( "implizite" gegeben). Se a percepção sensível encontra-se sempre em modo "simples" e, portanto, com apreensão direta e imediata do objeto sensível, as partes implicitamente presentes deste mesmo objeto não poderiam se revelar à percepção, pois isso somente seria possível através de outro ato (que talvez englobe aquele primeiro, mas que em todo caso é diferente dele). Mais precisamente, trata-se de um ato de "enlace" (ou de "articulação"), capaz de relacionar, num juízo, uma parte qualquer a outras partes (ou ao todo) do objeto apreendido em questão. Tal limite da percepção sensível impede que a "parte" implicitamente presente no objeto apreendido - possa ser, como esclarece Husserl no $\int 48$ da mesma Investigação, no ato simples desta percepção, realçada (ou explicitada) no seu "ser parte" (Teil-sein) (HUSSERL, [1901] 1913b, 1968, §48).

Em tal captação simples da percepção sensível, a parte implicitamente percebida na apreensão do objeto em seu "todo" não teria autonomia para se revelar, por si mesma, como um novo "objeto" (als neue "Objekt"). O limite em questão impõe um novo deslocamento, obrigando-nos a passar para um novo "caráter de ato" (neuen Aktcharakter). Nos termos de Husserl, trata-se de um ato articulador capaz de enlaçar, num juízo, os termos da proposição, relacionando, por conseguinte, por exemplo, uma "parte" ao "todo" do objeto visado, permitindo-nos, assim, pensar um "estado-de-coisa" deste objeto. Se a percepção sensível apreende, por exemplo, diretamente o objeto "A", cuja presença se evidencia imediatamente para um ato simples e fundante, a sua parte (digamos, " $\alpha$ ") somente poderia ser trazida à evidência enquanto um "novo objeto" na medida em que nos deslocássemos para um novo "caráter de ato", capaz de operar em uma esfera mereológica. Eis o que é próprio dos atos complexos e o que conduz Husserl à ampliação do conceito de "percepção", agora entendido, na esfera categorial, como "analogon da intuição sensível vulgar" ("das Analogon der gemeinen sinnlichen Anschauung”) (HUSSERL, [1901] 1913b, 1968, §44, p. 141). Falamos, a partir de então, de "percepção relacionante" (beziehenden "Wahrnehmung"). Tais atos apreendem um novo objeto (um "estado-de-coisa" visado) na medida em que articulam, num juízo, os termos da relação (no exemplo em questão, "A" e " $\alpha$ ") através de uma forma categorial objetiva, representada, numa asserção simples, pela palavrinha "é" (cuja função sintática consiste em enlaçar os referidos termos, ligando-os sinteticamente). Daí dizermos em uma ação judicativa: "A é $\alpha$ ". Tratar-se-á, a partir de agora, de trazer, na esfera dos atos objetivantes, tais formas judicativas à intuição (de trazê-las à evidência). $O$ ato complexo apreende um objeto cuja presença se evidencia "mediatamente" para o próprio ato e, neste sentido, dizemos que tais atos são "fundados" (fundierten Akten), diferentemente dos atos simples que são tão somente fundantes (daí Husserl considerá-los os mais fundamentais). Ainda que os atos complexos acrescentem, mediante sua capacidade articuladora, uma nova significação à coisa percebida sensivelmente, permitindo-nos pensar, ao asserir predicativamente algo sobre o objeto visado, um estado-de-coisa deste objeto, não deixam, contudo, enquanto atos complexos, de estarem fundados na percepção sensível, conforme 
atestam, mais originariamente, os "juízos de experiência" (Erfahrungsurteile), cujos termos da relação consistem em elementos materiais últimos presentes nos termos da asserção e que encontram preenchimento direto na própria intuição sensível.

Temos, então, conforme os termos empregados por Husserl (quase três décadas após a publicação da primeira edição de Investigações Lógicas), no \84 de Lógica Formal e Lógica Transcendental (1929), algo como uma "hierarquia de evidências" (Stufenfolge der Evidenzen) e, neste sentido, nos encontramos em condições de compreender a segunda tese sobre a evidência: "toda evidência predicativa implica em uma evidência pré-predicativa" (Prädikative Evidenz schließt vorprädikative ein). Quer dizer, implica, em última instância, caso façamos uma gênese do sentido dos juízos, em qualquer coisa visada, respectivamente, vista evidentemente (na esfera sensível) e expressa na esfera predicativa (primeiramente, nos "juízos de experiência"). O autor nos diz, no mesmo parágrafo, que a hierarquia dos julgamentos e de seus sentidos corresponde à hierarquia das evidências, de modo que "as verdades e as evidências primeiras em si devem ser as verdades e as evidências individuais" ("...die an sich ersten Wahrheiten und Evidenzen müssen die individuellen sein") (HUSSERL, [1929] 1981, p. 182). Quando seguimos o fio condutor da gênese do sentido, recuando até o seu nível mais baixo, deparamo-nos com "juízos sobre indivíduos" (Individualurteile), por meio dos quais temos a evidência de estados de coisas individuais. Neste sentido, nesta hierarquia, os juízos cuja evidência é, efetivamente, a mais originária devem ser a priori os "juízos de experiência" (Erfahrungsurteile), dirigidos sobre os dados da percepção. Trata-se de juízos sobre indivíduos que, por sua vez, nos são revelados diretamente pela experiência, aqui concebida, no sentido "primeiro" (ersten) e "mais forte" (prägnantesten), como "referência direta ao indivíduo" (als direkte Beziehung auf Individuelles) (HUSSERL, [1929] 1981, p. 183). Daí Husserl afirmar: "o que é primeiro em si em uma teoria dos julgamentos evidentes é o retorno genético das evidências predicativas à evidência não predicativa que se chama então experiência" (HUSSERL, [1929] 1981, p. 186) ${ }^{6}$. Esta última evidência entra no julgar que se encontra no nível o mais baixo do ponto de vista genético. Encontramo-nos frente ao começo primeiro em si de uma teoria sistemática do julgamento. Localizandonos neste começo é que podemos descobrir que a distinção entre intenção presumida e seu preenchimento não pertence exclusivamente à esfera predicativa, mas, supõe, no retorno predicativo da gênese do sentido, a experiência prépredicativa.

\section{CONSIDERAÇÕES FINAIS}

Como vimos, as duas teses sobre a evidência alinham-se, em Husserl, a um duplo deslocamento que, por sua vez, impõe-nos um duplo "acréscimo". Na primeira tese, passamos, pela evidência da presença da coisa visada (ou do seu

\footnotetext{
6 "Danach ist unter Gesichtspunkten dieser Genesis die an sich erste Urteilstheorie die Theorie der evidenten Urteile (und damit in einer Urteilstheorie überhaupt) die genetische Rückführung der prädikativen Evidenzen auf die nichtprädikative Evidenz, die da Erfahung heist".
} 
estado-de-coisa), do ato intencional meramente significativo para o seu preenchimento intuitivo. A evidência de uma dada presença é este "acréscimo", responsável pelo "caráter de preenchimento" do mero visar significativo. A tarefa de refletir sobre o alcance do que me é dado e, portanto, sobre os limites em jogo na evidenciação da coisa visada, antecede, conforme mostrado, a segunda tese. A atribuição do ser (em sentido predicativo) à coisa percebida sensivelmente, denuncia-nos um "acréscimo" de significação concernente a um "estado" da coisa visada e que não poderia encontrar, no ato simples da percepção sensível, um correspondente objetivo que pudesse confirmá-lo intuitivamente. Tal atribuição obriga-nos, conforme vimos, a um deslocamento para a esfera judicativa, na qual relacionamos, num juízo, os termos da proposição, permitindo-nos, enfim, pensar, como um "novo objeto", um estado-de-coisa. Temos, então, com as teses em questão, um duplo deslocamento, cada um dos quais impondo um "acréscimo" específico. Se a primeira tese coloca-nos frente à evidência como um "primeiro princípio" suposto pelo método fenomenológico, a segunda tese mostra-nos que, apesar do seu acréscimo de significação em relação à coisa percebida sensivelmente, a evidência predicativa implica na evidência pré-predicativa, contendo, portando, esta última, conforme atestam, mais originariamente, os juízos de experiência. Tal implicação destaca o lugar primordial e originário da experiência pré-predicativa, sem que tal destaque converta a posição da fenomenologia num empirismo vulgar, cujas teses incorrem em problemas de fundamentos, conforme Husserl nos mostrou, já nas origens da Filosofia Contemporânea, ao denunciar os contrassensos teóricos do psicologismo. Por fim, podemos ainda observar a relação indissociável entre as teses em questão, posto que a segunda desdobra-se da primeira. Ambas assumem, com isso, um caráter propedêutico à fenomenologia husserliana, uma vez que, respectivamente, remetem-nos para o "primeiro princípio" do método fenomenológico, bem como para o lugar originário da experiência pré-predicativa como começo primeiro em si quando tratamos de uma teoria sistemática do julgamento.

\section{REFERÊNCIAS}

DERRIDA, J. La voix et le phénomène. Paris: Presses Universitaires de France, 1972.

HUSSERL, E. Logische Untersuchungen. Zweiter Band. Teil I. "Untersuchungen zur Phänomenologie und Theorie der Erkenntnis”. Stuttgart, Tübingen: Max Niemeyer Verlag, ([1901] 1913a, 1968).

Logische Untersuchungen. Zweiter Band. Teil II. "Elemente einer phänomenologischen Aufklärung der Erkenntnis". Stuttgart, Tübingen: Max Niemeyer Verlag, ([1901] 1913b, 1968).

Erste Philosophie (1923/1924). Erster Teil. The Netherlands: Martinus Nijhoff, ([1923/1924] 1956).

Formale und transzendentale Logik. Versuch einer Kritik der logischen Vernunft. Tübingen: Max Niemeyer Verlag, ([1929] 1981). 
HUSSERL, E. Cartesianische Meditationen und Pariser Vorträge. Husserliana (Band I). Den Haag, Netherlands: Martinuos Nijhoff, ([1931/ 1929] 1973).

TOURINHO, C. D. C. Sobre a adequação entre intenção significativa e preenchimento intuitivo nas Investigações Lógicas de Husserl. In: Cognitio: Revista de Filosofia, v. 16, n. 2, 2015, pp. 361-374.

Recebido em: 10-06-2020

Aceito para publicação em: 03-07-20 